\title{
Synthesis of radioactively labelled CdSe/CdS/ZnS quantum dots for in vivo experiments
}

\author{
Gordon M. Stachowski ${ }^{1}$, Christoph Bauer ${ }^{1}$, Christian Waurisch ${ }^{1,2}$, Denise Bargheer ${ }^{3}$, \\ Peter Nielsen ${ }^{3}$, Jörg Heeren ${ }^{3}$, Stephen G. Hickey ${ }^{1,4}$ and Alexander Eychmüller ${ }^{* 1}$
}

\section{Full Research Paper}

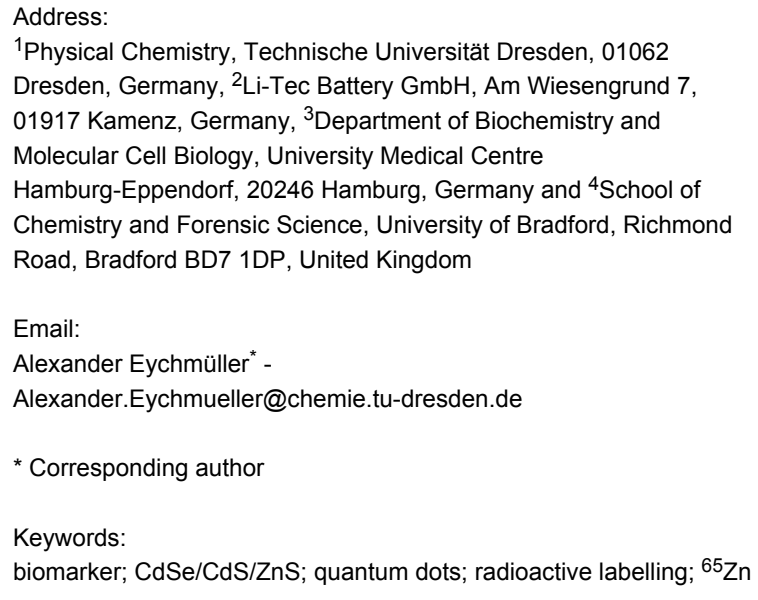

Beilstein J. Nanotechnol. 2014, 5, 2383-2387. doi:10.3762/bjnano.5.247

Received: 05 May 2014

Accepted: 17 November 2014

Published: 10 December 2014

This article is part of the Thematic Series "Biological responses to NPs".

Guest Editor: R. Zellner

(C) 2014 Stachowski et al; licensee Beilstein-Institut. License and terms: see end of document.

\begin{abstract}
During the last decades of nanoparticles research, many nanomaterials have been developed for applications in the field of biolabelling. For the visualization of transport processes in the body, organs and cells, luminescent quantum dots (QDs) make for highly useful diagnostic tools. However, intercellular routes, bio-distribution, metabolism during degradation or quantification of the excretion of nanoparticles, and the study of the biological response to the QDs themselves are areas which to date have not been fully investigated. In order to aid in addressing those issues, $\mathrm{CdSe} / \mathrm{CdS} / \mathrm{ZnS}$ QDs were radioactively labelled, which allows quantification of the QD concentration in the whole body or in ex vivo samples by $\gamma$-counting. However, the synthesis of radioactively labelled QDs is not trivial since the coating process must be completely adapted, and material availability, security and avoidance of radioactive waste must be considered. In this contribution, the coating of CdSe/CdS QDs with a radioactive ${ }^{65} \mathrm{ZnS}$ shell using a modified, operator-safe, SILAR procedure is presented. Under UV illumination, no difference in the photoluminescence of the radioactive and non-radioactive $\mathrm{CdSe} / \mathrm{CdS} / \mathrm{ZnS}$ colloidal solutions was observed. Furthermore, a down-scaled synthesis for the production of very small batches of $5 \mathrm{nmol}$ QDs without loss in the fluorescence quality was developed. Subsequently, the radiolabelled QDs were phase transferred by encapsulation into an amphiphilic polymer. $\gamma$-counting of the radioactivity provided confirmation of the successful labelling and phase transfer of the QDs.
\end{abstract}




\section{Introduction}

Two decades of research and investigation in the field of luminescent semiconductor nanoparticles, also known as quantum dots (QDs), have now passed since the fundamental work of Bawendi and co-workers, which focused particularly on the synthesis of II-VI materials [1-5]. CdSe-based, state-of-the-art synthetic protocols typically use the hot injection method [1] and can deliver QDs with visible emission which possess quantum yields (QYs) of up to $85 \%$ as core/shell or alloyed structures [5-8]. Semiconductor nanocrystals are discussed in the literature as potential emitters for LEDs or as bio-labelling agents due to their complementary optical properties as well as other advantages in comparison to organic dyes. For example, they exhibit broad absorption (allowing excitation energies higher than the band gap energy to be freely selected), narrow emission spectra, long emission lifetimes, photo- and chemicalstability, etc. $[5,9,10]$.

Although they offer many advantages, it is important to evaluate the toxicity [11] of nano-scale materials, particularly for biological applications and to comply with the necessary safety and regulatory aspects. One main issue is their chemical toxicity due to their composition, as QDs with high QYs often contain $\mathrm{Cd}^{2+}$ or $\mathrm{Hg}^{2+}$, and their metabolism results in the release of toxic ions. This work represents a contribution to the investigation of the intercellular route taken by QDs, the quantification of the degradation or excretion of the nanoparticles, and the study of the biological response to QDs.

To address those issues, a methodology for radioactively labelling of QDs was developed. Applying this strategy enables the quantification of the QD concentration during cellular uptake to be calculated. Here, the measured amount of radioactivity can be related to the amount or concentration of the QD ensemble or their metabolites (i.e., ionic species). To avoid any potential chemical inconsistencies we replace the typical precursors present in the synthesis with their equivalent radionuclides. In the past, radionuclides such as ${ }^{109} \mathrm{Cd}$ or ${ }^{111}$ In were used for intrinsic radiolabeling $[12,13]$. In this work, the $\mathrm{Zn}$ component of $\mathrm{CdSe} / \mathrm{CdS} / \mathrm{ZnS}$ core/shell/shell QDs was selected for replacement with ${ }^{65} \mathrm{Zn}$ due to its ease of availability. Furthermore, due to the frequency with which $\mathrm{ZnS}$ is used as a shell material, the selection of ${ }^{65} \mathrm{Zn}$ allows the variation of the core, offering a higher degree of versatility for the method.

The well-investigated CdSe-based QDs were utilised as a model system onto which $\mathrm{CdS}$ and $\mathrm{ZnS}$ are coated via the successive ion layer adsorption and reaction method (SILAR) in order to achieve greater chemical stability, an enhancement of the fluorescence QY and a shift in the photoluminescence (PL) wavelength to the therapeutic spectral window $[3,6,8]$.
When developing a synthesis for radioactively labelled QDs, one must take into account the handling under typical chemical laboratory conditions with respect to both the safety aspects and material availability. Moreover, the common chemical laboratory synthesis batch size must be scaled down to avoid excessive radioactive waste while ensuring a statistically relevant probability of adequate labelling. Finally, for in vivo experiments the radioactively labelled QDs must be quantitatively and qualitatively transferred into the aqueous phase.

\section{Results and Discussion Radioactive synthesis}

For the synthesis of radioactively labelled material, it was necessary to significantly alter the coating process from the routine SILAR protocol. The main challenges were to use ${ }^{65} \mathrm{ZnCl}_{2}$ as the radioactive zinc precursor instead of the commonly used $\mathrm{ZnO}$ or $\mathrm{Zn}$ (oleate) ${ }_{2}$ in the SILAR synthetic routes and to reduce the contact time involved in the handling of the radioactive material as much as possible. For this purpose, ${ }^{65} \mathrm{ZnCl}_{2}$ diluted in $0.1 \mathrm{M} \mathrm{HCl}_{(\mathrm{aq})}$ was placed in an empty, lead glass shielded flask where it was converted to a species more useful for the labelling of CdSe/CdS QDs by the in situ formation of zinc stearate $\left.\left({ }^{65} \mathrm{Zn} \text { (stearate) }\right)_{2}\right)$. After addition of the previously prepared QD materials and adsorption of ${ }^{65} \mathrm{Zn}^{2+}$ onto the QD surface, the sulphur precursor was added to the flask to form a shell of ${ }^{65} \mathrm{ZnS}$. To avoid later desorption of radioactive ${ }^{65} \mathrm{Zn}^{2+}$ ions from the surface, another $\mathrm{ZnS}$ shell (using a nonradioactive zinc precursor) was applied to the QDs using the typical SILAR procedure (Figure 1A) [6,8]. The main advantage of this method is that the radioactive material can be added at ambient temperature and shielded by lead glass using a pipette, which prevents direct hand contact from the very beginning. All other materials may be added safely from a sufficient distance and behind lead glass.

A red shift in the absorbance and PL spectra indicates the formation of a CdS shell surrounding the CdSe QDs (Figure 1B). During the formation of the non-radioactive $\mathrm{ZnS}$ shell, a slight blue shift and a weakening of the absorbance was observed. Due to the radioactivity and safety issues, spectra could not be taken for the $\mathrm{CdSe} / \mathrm{CdS} /{ }^{65} \mathrm{ZnS} / \mathrm{ZnS}$ QDs. However, the PL of both the cleaned $\mathrm{CdSe} / \mathrm{CdS} / \mathrm{ZnS}$ and the $\mathrm{CdSe} / \mathrm{CdS} /{ }^{65} \mathrm{ZnS} / \mathrm{ZnS}$ QDs show no significant difference under UV illumination (Figure 1C) with the PL remaining unchanged even after one month. The radiation due to the ${ }^{65} \mathrm{Zn}$ decay does not appear to influence the PL intensity to any great extent.

By quantification of the radioactivity of the ${ }^{65} \mathrm{Zn}$-containing QDs it was found that only $50 \%$ of the original ${ }^{65} \mathrm{Zn}$ was detected in the cleaned QD solution, the rest being accounted 

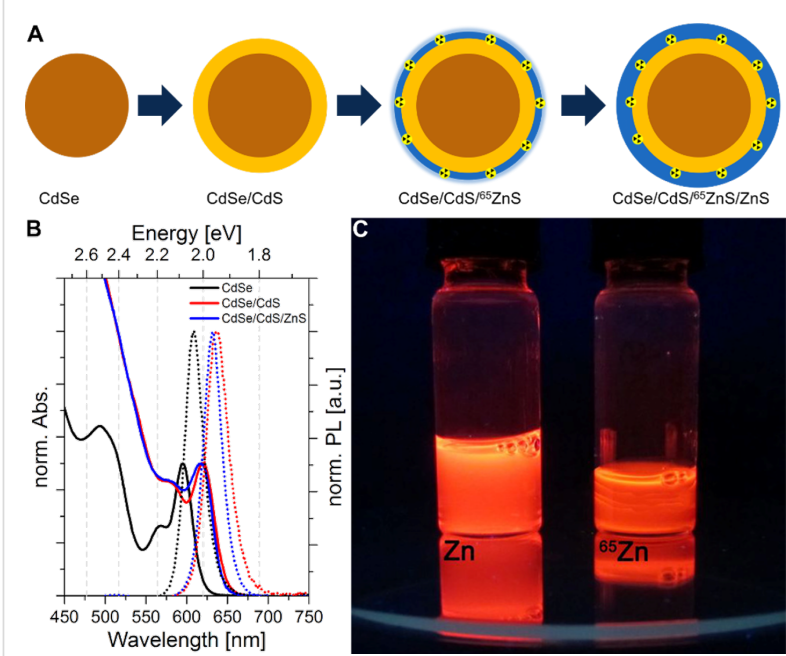

Figure 1: (A) Principle steps in the QD synthesis starting with the CdS coating of CdSe QDs and followed by stepwise application of ${ }^{65} \mathrm{ZnS}$ and ZnS shells. (B) Absorbance (solid) and PL (dotted) spectra of $\mathrm{CdSe}, \mathrm{CdSe} / \mathrm{CdS}$ and non-radioactive CdSe/CdS/ZnS QDs. (C) Colloidal QD solutions of non-radioactive CdSe/CdS/ZnS (left) and radioactive $\mathrm{CdSe} / \mathrm{CdS} /{ }^{65} \mathrm{ZnS} / \mathrm{ZnS}$ (right) under illumination by a UV lamp.

for by the waste reaction and purification solution. Moreover, the non-radioactive QDs were investigated using TEM (Figure 2) and interestingly, instead of an expected size increase [8] of two monolayers of $\mathrm{ZnS}(\approx 1.2 \mathrm{~nm})$, a nominal increase of only one monolayer was observed. Both effects point to an incomplete coating of the $\mathrm{ZnS}$ shells but the exact reason has yet to be determined.
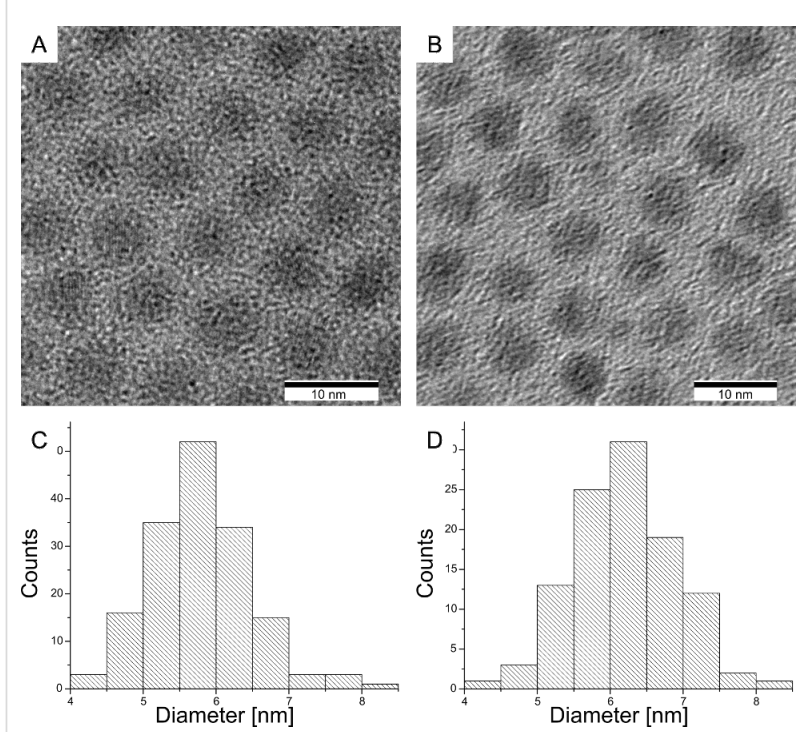

Figure 2: TEM images and associated size histograms of the $\mathrm{CdSe} /$ CdS QDs $(A, C)$ and CdSe/CdS/ZnS (B,D) which show the diameter of the $Q D$ s to be $5.8 \mathrm{~nm} \pm 0.7 \mathrm{~nm}$ and $6.4 \mathrm{~nm} \pm 0.7 \mathrm{~nm}$, respectively. Scale bars are $10 \mathrm{~nm}$.

\section{Minimization}

The amount of radioactive material that is required in order to produce a viable amount of material per batch is another very important aspect in the development of the synthesis. The amount of QDs typically produced on the lab scale via a hot injection process far exceeds the desired requirements for most biological experiments (Figure 3A). From the point of view of safety during the synthesis and subsequent bio-applications, the amount of radioactively labelled material should be kept to a minimum. Similarly, from an environmental perspective, in order to avoid radioactive waste, one must work with as small a batch as possible. Furthermore, while overloading the QDs with radioactive material should be avoided, the final synthesis design should guarantee an adequate degree of radioactivity per particle in order to avoid the statistical probability that an unnecessarily large amount of QDs remain unlabelled (B instead of $\mathrm{C}$ in Figure 3).

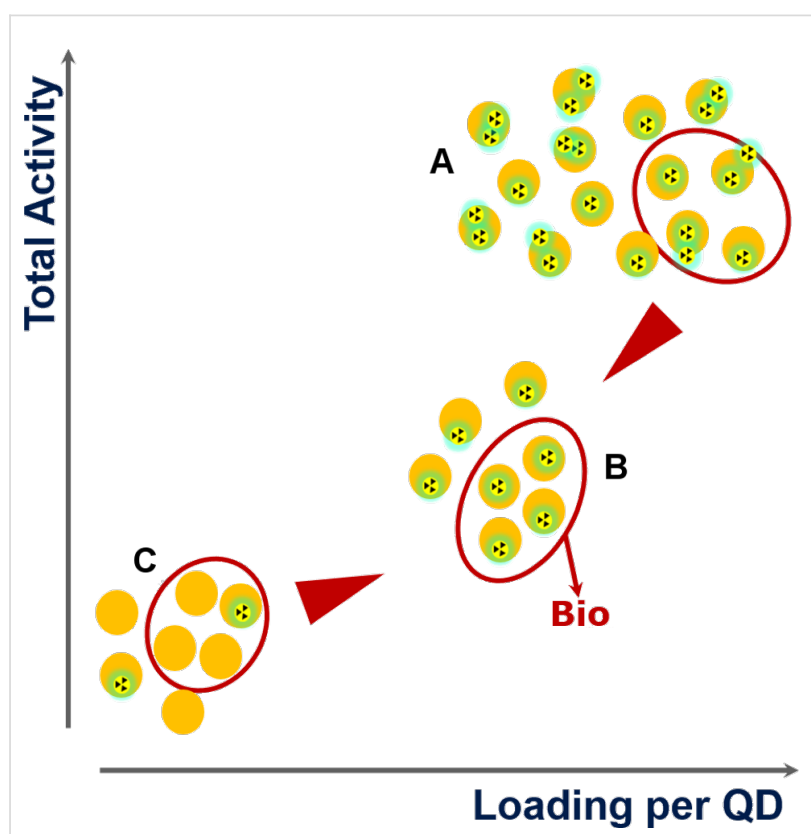

Figure 3: (A) shows excessive labelling and a large quantity of QDs which is not necessary for bio-applications. It is desirable to decrease the total amount of radioactivity $(A \rightarrow B)$ by reducing the excessive labelling (diminish the per-particle-loading) and the total amount of QDs simultaneously. (C) represents the presence of non-labelled QDs and should be avoided.

In light of the above considerations, down-scaling entails the design of a completely new synthesis route which includes the optimization of the typical synthesis parameters such as batch size, relative concentrations, injection and ripening temperatures, etc. By contrast, due to the extremely small volumes and masses involved, the down-scaling is limited by the degree of control over the stirring rates and temperature. A judicious modification of the protocol with respect to the ratio of reac- 
tants, ligands and solvents allows the synthesis procedure to be scaled down to amounts of $\mathrm{CdSe} / \mathrm{CdS}$ QDs on the order of $5 \mathrm{nmol}$.

Furthermore the procedure has been designed to enable the operator to vary the ratio between ${ }^{65} \mathrm{ZnS}$ and $\mathrm{ZnS}$ in the inner shell, by addition of non-radioactive $\mathrm{ZnCl}_{2}$ or $\mathrm{Zn}$ (stearate) $)_{2}$, in order to be able to attain a predefined ratio, thus allowing one to choose the specific radioactivity in the ${ }^{65} \mathrm{ZnS}$ (inner) shell. For example, in a typical $5 \mathrm{nmol}$ batch with a desired final radioactivity of $5 \mu \mathrm{Ci}$, it was possible to choose the ratio of ${ }^{65} \mathrm{ZnCl}_{2}$ and $\mathrm{ZnCl}_{2}$ to be very close to $1: 10$. By comparison, a single application of co-labelled QDs in in vivo experiments demands $1 \mu \mathrm{Ci}$ per mouse.

\section{Phase transfer}

The synthesis of $\mathrm{CdSe} / \mathrm{CdS} /{ }^{65} \mathrm{ZnS} / \mathrm{ZnS}$ QDs was carried out in organic media. However, to extend their potential range of application, the nanoparticles should be dispersible in biologically compatible, aqueous media. Therefore, an encapsulation and phase transfer method described by Shtykova et al. was used to introduce the QDs, stabilized by nonpolar ligands, into an amphiphilic polymer [14]. Under UV illumination, similar emission colours for both, the hydrophilic, encapsulated and the hydrophobic QDs were detected, which is evidence for the success of the encapsulation as well as the fact that nanoparticles remain uncompromised during the wrapping procedure. However, it was found by $\gamma$-counting of radioactivity that a dramatic decrease of about $90 \%$ occurred during the encapsulation step. Initial studies suggest that the decrease in radioactive activity during the encapsulation and phase transfer steps appears to be due to the harsh ultra-sonication of the QDs during the procedure. The possibility of employing less energy intensive methods such as shaking or stirring is currently under investigation.

\section{Conclusion}

A method for the labelling of $\mathrm{CdSe} / \mathrm{CdS} / \mathrm{ZnS}$ QDs during the synthesis process with radioactive ${ }^{65} \mathrm{Zn}$ in one of the outer shells of the nanoparticles has been developed. The challenges associated with the handling of radioactive materials and the minimization of the synthesis in order to avoid excessive generation of radioactive waste have been resolved. To this effect, a procedure strategy was designed where the main advantage is a high degree of operator safety and the avoidance of direct hand contact with the radioactive materials. Further, by varying the amounts of ${ }^{65} \mathrm{ZnCl}_{2}$ and $\mathrm{ZnCl}_{2}$, the radioactivity per particle can be controlled. Interestingly, we observed a ${ }^{65} \mathrm{ZnS}$ shell formation which was thinner than expected the thickness, resulting in a lower ${ }^{65} \mathrm{Zn}$ incorporation, the exact origin of which is currently under investigation.
The process of encapsulation and phase transfer causes a high loss in radioactivity, which is suspected to be due to the harsh sonication conditions. Quantification of the QD solution via absorption and PL measurements should help to understand the mechanism involved during this step. Phase transfer strategies should be pursued in order to allow comparison of differently transferred QDs for their in vivo response.

Owing to its decay, ${ }^{65} \mathrm{Zn}$ is transformed into $\mathrm{Cu}$ and therefore over time the amount of $\mathrm{CuCl}_{2}$ present in the ${ }^{65} \mathrm{ZnCl}_{2}$ containing $0.1 \mathrm{M} \mathrm{HCl}_{(\mathrm{aq})}$ increases. It is clear that when $\mathrm{CuCl}_{2}$ is present in the initial reaction mixture it can be transformed to $\mathrm{Cu}$ (stearate) $)_{2}$ during the transformation [15] of the ${ }^{65} \mathrm{ZnCl}_{2}$, however, the degree of transformation is unknown. The decay of ${ }^{65} \mathrm{Zn}$ occurs in the QDs and the influence of $\mathrm{Cu}$ in the coating layer of the QDs should be more fully investigated in terms of its lattice mismatch, self-purification and optical properties (e.g., dopant emission, PL enhancement or quenching).

\section{Experimental Synthesis of CdSe/CdS QDs}

Into a $25 \mathrm{~mL}$ three-neck flask, $10 \mathrm{~mL}$ of 1-octadecene (ODE), $0.4 \mathrm{mmol}$ of $\mathrm{Cd}$ (oleate) ${ }_{2}$ as a stock, $2 \mathrm{~g}$ hexadecylamine and $2 \mathrm{~g}$ trioctylphosphine oxide was loaded. After degassing, the temperature was set to $270{ }^{\circ} \mathrm{C}$ and $0.4 \mathrm{mmol}$ of trioctylphosphine selenide (TOP:Se) as a stock was injected rapidly under an Ar flow. After remaining for $20 \mathrm{~min}$ at $245^{\circ} \mathrm{C}$, the reaction was quenched with toluene and the CdSe QDs were purified.

$100 \mathrm{nmol}$ of the purified QDs $(4.3 \mathrm{~nm}), 1.5 \mathrm{~g}$ of octadecylamine (ODA) and $6 \mathrm{~mL}$ of ODE were placed in a $25 \mathrm{~mL}$ threeneck flask and degassed. At $220^{\circ} \mathrm{C}$, cation and anion precursors, $\mathrm{Cd}(\text { oleate })_{2}$ and $\mathrm{S}$ as an ODE stock solution (ODE:S), were added alternating with waiting times of 5 and 25 min after each injection, respectively. The amounts were calculated based on the addition of two times one monolayer for the given size of the CdSe QDs.

\section{Synthesis of $\mathrm{CdSe} / \mathrm{CdS} /{ }^{65} \mathrm{ZnS} / \mathrm{ZnS}$ QDs}

The following specifications are calculated for a certain radioactivity of ${ }^{65} \mathrm{ZnCl}_{2}$ containing $0.1 \mathrm{M} \mathrm{HCl}$, namely, $556 \mu \mathrm{g}$ ${ }^{65} \mathrm{Zn} /(\mathrm{mL} \mathrm{HCl})$ and $122 \mu \mathrm{Ci} /(\mathrm{mL} \mathrm{HCl})$. A $25 \mathrm{~mL}$ three-neck flask shielded with lead glass was loaded with $4.0 \mu \mathrm{mol}$ of $\mathrm{ZnCl}_{2}\left(92 \%\right.$ of total $\left.\mathrm{ZnCl}_{2}\right)$ diluted in methanol and $41.2 \mu \mathrm{L}$ of a ${ }^{65} \mathrm{ZnCl}_{2} / \mathrm{HCl}$ solution $\left(22.9 \mu \mathrm{g}{ }^{65} \mathrm{Zn}, 0.35 \mu \mathrm{mol}{ }^{65} \mathrm{Zn}, 8 \%\right.$ of total $\mathrm{ZnCl}_{2}, 5 \mu \mathrm{Ci}$ ). The $\mathrm{HCl}$ and $\mathrm{H}_{2} \mathrm{O}$ were then evacuated from the flask. A mixture of $30.6 \mu$ mol stearic acid and $17.5 \mu \mathrm{mol}$ tetramethylammonium hydroxide in methanol was added dropwise. The precipitated ${ }^{65} \mathrm{Zn}$ (stearate) ${ }_{2}$ was then dried under vacuum. For the particle coating, as adopted from $\mathrm{Li}$ et al. [6], $5 \mathrm{nmol}$ of the previously prepared CdSe/CdS QDs $(5.7 \mathrm{~nm})$, 
$50 \mathrm{mg}$ of ODA and $2 \mathrm{~mL}$ of ODE were added and the solution was placed under inert gas atmosphere. Under room temperature, $50 \mu \mathrm{L}$ of a $0.1 \mathrm{M}$ ODE:S stock solution was added and the temperature was set to $220{ }^{\circ} \mathrm{C}$ for the coating step. After $30 \mathrm{~min}, 60 \mu \mathrm{L}$ of a $0.1 \mathrm{M} \mathrm{Zn}$ (oleate) 2 , and $35 \mathrm{~min}$ thereafter $100 \mu \mathrm{L}$ of $0.1 \mathrm{M}$ ODE:S, were added dropwise at $200{ }^{\circ} \mathrm{C}$. After $60 \mathrm{~min}$ the reaction was quenched with $2 \mathrm{~mL}$ of toluene. In comparison to typical clean-up procedures for non-radioactive QDs, only two precipitation steps were performed behind lead glass to purify radioactive QDs to avoid large amounts of radioactive waste. The amount of ${ }^{65} \mathrm{ZnCl}_{2}$ solution and other components used for the coating must be adjusted with respect to the concentration and size [8] of the CdSe/CdS QDs that are used. Radioactive waste was temporarily stored and collected by an authorized waste management enterprise under appropriate safety precautions.

\section{Measurements}

For absorption and emission spectroscopy, a Cary 50 Scan (Varian) and a Fluoromax 4 (Horiba), respectively, were used. TEM was performed on a Libra 200 (Zeiss) instrument. For radioactivity analysis, the Hamburg Whole Body Radioactivity Counter [16] was used to measure ${ }^{65} \mathrm{Zn}$ radioactivity.

\section{Acknowledgements}

This work was supported by grants from the Deutsche Forschungsgemeinschaft for the groups of Peter Nielsen, Alexander Eychmüller and Jörg Heeren in the NANOFATE-Cluster (SPP1313, Hepatic processing and biological response to nanocrystals in vivo). TEM was performed using the Zeiss Libra 200 at the IPF Dresden, Germany.

\section{References}

1. Murray, C. B.; Norris, D. J.; Bawendi, M. G. J. Am. Chem. Soc. 1993, 115, 8706-8715. doi:10.1021/ja00072a025

2. Talapin, D. V.; Rogach, A. L.; Kornowski, A.; Haase, M.; Weller, H. Nano Lett. 2001, 1, 207-211. doi:10.1021/nl0155126

3. Xie, R.; Kolb, U.; Li, J.; Basché, T.; Mews, A. J. Am. Chem. Soc. 2005, 127, 7480-7488. doi:10.1021/ja042939g

4. Zhong, X.; Feng, Y.; Zhang, Y. J. Phys. Chem. C 2007, 111, 526-531. doi:10.1021/jp064797d

5. Mekis, I.; Talapin, D. V.; Kornowski, A.; Haase, M.; Weller, H. J. Phys. Chem. B 2003, 107, 7454-7462. doi:10.1021/jp0278364

6. Li, J. J.; Wang, Y. A.; Guo, W.; Keay, J. C.; Mishima, T. D.; Johnson, M. B.; Peng, X. J. Am. Chem. Soc. 2003, 125, 12567-12575. doi:10.1021/ja0363563

7. Bae, W. K.; Char, K.; Hur, H.; Lee, S. Chem. Mater. 2008, 20 , 531-539. doi:10.1021/cm070754d

8. Reiss, P.; Protière, M.; Li, L. Small 2009, 5, 154-168. doi:10.1002/smll.200800841

9. Dubavik, A.; Sezgin, E.; Lesnyak, V.; Gaponik, N.; Schwille, P.; Eychmüller, A. ACS Nano 2012, 6, 2150-2156. doi:10.1021/nn204930y
10. Otto, T.; Müller, M.; Mundra, P.; Lesnyak, V.; Demir, H. V.; Gaponik, N.; Eychmüller, A. Nano Lett. 2012, 12, 5348-5354. doi:10.1021/nl3027444

11. Tsoi, K. M.; Dai, Q.; Alman, B. A.; Chan, W. C. W. Acc. Chem. Res. 2013, 46, 662-671. doi:10.1021/ar300040z

12. Sun, M.; Hoffman, D.; Sundaresan, G.; Yang, L.; Lamichhane, N. Am. J. Nucl. Med. Mol. Imaging 2012, 2, 122-135.

13. Sun, M.; Sundaresan, G.; Jose, P.; Yang, L.; Hoffman, D.; Lamichhane, N.; Zweit, J. J. Mater. Chem. B 2014, 2, 4456-4466. doi:10.1039/c4tb00296b

14. Shtykova, E. V.; Huang, X.; Gao, X.; Dyke, J. C.; Schmucker, A. L.; Dragnea, B.; Remmes, N.; Baxter, D. V.; Stein, B.; Konarev, P. V.; Svergun, D. I.; Bronstein, L. M. J. Phys. Chem. C 2008, 112, 16809-16817. doi:10.1021/jp8053636

15. Pradhan, N.; Peng, X. J. Am. Chem. Soc. 2007, 129, 3339-3347. doi:10.1021/ja068360v

16. Braunsfurth, J. S.; Gabbe, E. E.; Heinrich, H. C. Phys. Med. Biol. 1977, 22, 1-17. doi:10.1088/0031-9155/22/1/002

\section{License and Terms}

This is an Open Access article under the terms of the Creative Commons Attribution License (http://creativecommons.org/licenses/by/2.0), which permits unrestricted use, distribution, and reproduction in any medium, provided the original work is properly cited.

The license is subject to the Beilstein Journal of

Nanotechnology terms and conditions:

(http://www.beilstein-journals.org/bjnano)

The definitive version of this article is the electronic one which can be found at: doi:10.3762/bjnano.5.247 